\title{
Vestida para o lazer: a descrições da moda nas crônicas mundanas de João do Rio
}

Heloísa Leite Imada

Mestranda, Universidade Estadual de Campinas / helo imada@hotmail.com Orcid: 0000-0002-6172-4024 / lattes

\section{Orna Messer Levin}

Doutora, Universidade Estadual de Campinas / orna.levin@gmail.com Orcid: 0000-0002-3322-3927 / lattes

Enviado: 16/10/2019 // Aceito: 16/12/2019 


\title{
Vestida para o lazer: a descrições da moda nas crônicas mundanas de João do Rio
}

\begin{abstract}
RESUMO
$\mathrm{Na}$ historiografia recente, é consensual a visão de que as reformas modernizadoras promovidas no Rio de Janeiro no início do século XX alteraram a arquitetura da capital federal e a relação da população com a experiência urbana, introduzindo novas práticas no cotidiano dos cariocas. Dentre as novidades incorporadas, encontram-se as práticas de esporte. A imprensa periódica constituiu o principal veículo de representação de tais práticas esportivas. O presente trabalho tem por objetivo analisar a presença da moda esportiva nas crônicas mundanas e examinar sua contribuição para a validação de um imaginário coletivo acerca do lazer. O enquadramento do figurino esportivo ganha complexidade na "civilização do jornal", na qual as relações sociais passam a ser reguladas pela produção e pela leitura dos impressos. Busca-se, portanto, mapear o acesso aos paradigmas fashion por parte das leitoras (mulheres) de periódicos. Como estudo de caso, são analisadas duas crônicas mundanas de João do Rio sobre a temática esportiva. Publicadas na coluna A Semana Elegante em 1916, estas abordam a presença feminina e sua indumentária na prática do tênis e dos banhos de mar. Assim, pretende-se mostrar como a importação e a representação das práticas esportivas e sua moda atuaram na construção de um imaginário de elegância na cidade do Rio de Janeiro.
\end{abstract}

Palavras-chave: Crônica mundana. João do Rio. Moda. 


\title{
Dressed for leisure: the fashion descriptions in the mondaine chronicles of João do Rio
}

\begin{abstract}
In recent historiography, there is a consensus that the modernizing reforms promoted in Rio de Janeiro at the beginning of the 20th century have changed the capital's architecture and the relationship between its population and the urban experience, introducing new practices into daily lives of cariocas. Among them was the introduction of sports, with the press being the main vehicle for its dissemination. This article explores the presence of fashion dedicated to sports in chronicles and examines its contribution to the validation of a collective imagination about leisure. The literary representation of sportswear gains complexity in the "civilisation du journal", in which social relations are regulated by the production and reading of magazines. Therefore, the aim is to map out the access to fashion paradigms by readers of periodicals. As a case study, two chronicles of João do Rio on the sports theme are analyzed. Published in the column "A Semana Elegante" in 1916, they focus on the female presence and their clothing in the practice of tennis and sea bathing. We conclude that the importation and representation of sports practices and their fashion acted in the construction of an imaginary of elegance in the city of Rio de Janeiro.
\end{abstract}

Keywords: Literature. Chronicle. João do Rio. Fashion. 


\title{
Vestida para el ocio: descripciones de moda en las crónicas mundanas de João do Rio
}

\begin{abstract}
RESUMEN
En la historia reciente, es consensual una visión de que como reformas modernizadoras promovidas en Río de Janeiro, no inicio del século XX, alterar una arquitectura de capital federal y una relación de población con una experiencia urbana, introducción de novas práticas no cotidianas dos cariocas. Dentre as novidades incorporadas, encontram-se as práticas de esporte. A imprensa periódica constituiu o principal veículo de representación de tais práticas esportivas. O presente trabalho tem por objetivo analisar a presença da fashion esportiva nas crônicas mundanas y examinar sua contribição for a validação de um imaginário coletivo acerca do lazer. O enquadramento do figurino esportivo ganha complexidade na "civilização do jornal", na qual as relações sociais passam a ser reguladas pela produção e pela leitura dos impressos. Busca-se, portanto, mapear o acesso aos paradigmas fashion por parte das leitoras (mulheres) de periódicos. Como estudo de caso, são analisadas duas crônicas mundanas de João do Rio sobre a temática esportiva. Publicadas na coluna A Semana Elegante en 1916, estas abordam a presença feminina e sua indumentária na prática do Tênis e dos banhos de mar. Assim, pretende-se mostrar como una importación y una representación de las prácticas deportivas y su moda en la construcción de un imaginario de elegibilidad en la ciudad de Río de Janeiro.
\end{abstract}

Palabras clave: crónica mundana. João do Rio. Moda. 


\section{INTRODUÇÃO}

Periódicos ilustrados têm se mostrado uma fonte irradiadora de conhecimento histórico. De suas páginas emanam os rastros das referências que moldaram a cultura dos impressos na modernidade. O manancial de recursos textuais e imagéticos que oferecem nos permite apreender, de maneira quase singular, a dinâmica dos fenômenos basilares da cultura que os estudiosos designaram de midiática (PINSON, 2008; KALIFA et al., 2011). A expansão da popularidade dos periódicos originou gêneros literários novos, a exemplo da crônica, por meio dos quais é possível compreender melhor o processo de constituição coletiva da noção de vida moderna (BENJAMIN, 1989, 1995). A circulação transnacional dos impressos responde, por sua vez, pela inserção dos leitores do Rio de Janeiro no circuito de leitura dos periódicos de cultura.

A rápida expansão da imprensa, durante o século XIX, introduziu mudanças estruturais que vão muito além da mera criação de um novo suporte para os textos. As inovações dos jornais induziram uma verdadeira mutação no sistema de escrita, afetando de uma só vez os regimes de leitura e escrita (THÉRENTY, 2003). Instituiu-se com a nova matriz de publicações diárias uma regularidade antes inexistente, uma rotina, que impactou a sociedade como um todo. A leitura regulada pela produção de periódicos impôs ritmo aos afazeres, emprestando cadencia às atividades de rotina. Ao se tornar um ato cotidiano, a leitura estabeleceu uma nova ordem temporal, pela qual se guiaram práticas e representações sociais. A partir do século XIX, a imprensa moldou a experiência urbana, determinada pelo ritmo da escrita e da leitura de periódicos. Da política aos eventos sociais, da filosofia às ciências, todos os temas foram 
abalados pela emergência da imprensa profissional cujo norte era dado pela cobertura da atualidade.

Segundo Thérenty, as categorias literárias serviram de molde para a invenção da poética jornalística. Considerando a escrita dos periódicos como um objeto literário, a pesquisadora lançou um olhar sobre os métodos poéticos, retóricos e linguísticos utilizados na construção de um modo de narrar próprio aos periódicos. Compostos a partir de recursos literários, os textos jornalísticos compreendem, a seu ver, quatro características: a fragmentação, a coletividade e a periodização em que se manifestam ou se modificam na relação com a atualidade, conforme detalharemos a seguir.

Em primeiro lugar, precisamos considerar, de acordo com Thérenty, que a escrita jornalística se insere em um enquadramento rigoroso, no qual a formatação funciona como regra poética. Os textos devem seguir uma estrutura de organização para a adequação ao mise-en-page do jornal. O rigor estrutural promoveu a formatação fragmentária de gêneros textuais, tais como o romancefolhetim, os poemas em prosa e a crônica. Em segundo lugar, temos de levar em conta a coletividade da escrita jornalística. Cada artigo se constrói dentro de um sistema de ecos estruturais, temáticos e ideológicos em diálogo com o restante do jornal. A multiplicidade de temas e a comunicação entre os espaços internos representam, textualmente, a realidade, de modo que essa pluralidade mimetiza a divisão e a organização da própria vida em sociedade. Em terceiro lugar, devemos atentar para a periodicidade da escrita jornalística. A leitura do jornal se repete sem parar, em intervalos regulares, dentro de uma temporalidade homogênea. Essa leitura pressupõe a constância do leitor, para que ele acompanhe o desenrolar 
das narrativas feitas pela imprensa. E, por fim, a estudiosa constata que a escrita jornalística é uma escrita referencial que deve ser pensada em sua proximidade com os acontecimentos da atualidade da qual é parte integrante e constitutiva. Além disso, depende do progresso técnico dos meios de comunicação e dos meios de transporte, bem como das regras políticas, isto é, depende da censura ou da liberdade de circulação das informações, entre outros fatores contextuais.

A articulação das quatro características que compõem a escrita jornalística definida por Thérenty explica a nova forma de produção e circulação da literatura, de modo a relacionar o jornal à poética, à retórica e à linguagem. A partir dos conceitos propostos em seu estudo, podemos situar os periódicos como meio de instauração da temporalidade moderna, organizada em torno da produção e da recepção dos impressos nas grandes cidades.

Vale notar, também, que a civilização urbana está diretamente ligada ao florescimento da era midiática. A imprensa modificou as formas pelas quais as sociedades passaram a registrar e a transmitir suas histórias. Os periódicos se firmaram, por essa razão, como um dos instrumentos coletivos de organização da sociabilidade. Em suas páginas, encontramos um conjunto de representações coletivas próprias às sociedades e um conjunto de práticas sociais necessárias à sua produção, difusão e recepção.

Ora, o jornal pretende descrever o cotidiano. O problema de organização dessa matéria, múltipla por natureza, se impõe ao diretor do jornal: como hierarquizar as informações? Organizá-las a partir de quais critérios? Como moldar a informação em virtude da seleção do que deva ser dito e do que não deva ser dito? Como dizer? O jornal não 
dá um tratamento cronológico ou temático às informações, mas sim privilegia uma escolha mista.

Para ordenar o todo segmentado criam-se as rubricas. As rubricas são espaços permanentes atribuídos a certo tipo de forma ou de escrita dentro dos periódicos. Elas manifestam a temporalidade dos impressos, pois estabelecem uma continuidade de leitura, de edição em edição, cujo efeito é a criação de um quadro no qual a vida cotidiana se torna legível. Os fragmentos se sucedem e um traço separa as unidades textuais. As rubricas são intituladas, a fim de estabelecer uma ordem estável e poder direcionar a leitura. "Política", "Estrangeiro", "Variedades", "Espetáculos", "Folhetim" e "Crônica" exemplificam os títulos comuns que preenchiam os periódicos brasileiros.

Apesar de existirem distinções na forma e no conteúdo, havia uma porosidade nas fronteiras entre as rubricas, que permitia pensar o jornal e as revistas como inventários. Esses sistemas complexos, compostos por pequenos excertos de interesse do corpo social, atraiam cada vez mais o olhar das camadas letradas da população.

Nesse artigo, nos dedicaremos à rubrica da crônica no período da Belle Époque. Ao contrário das rubricas teatrais e políticas, que preservavam a mesma configuração e abordagem temática do século XIX, a crônica se revela um gênero jornalístico inconstante e variado. Não se limita a uma forma genérica estável ou facilmente descritível. Caracteriza-se, ao contrário, pela autonomia do narradorcronista, que simula transitar pelos fatos cotidianos e pelos acontecimentos banais, recriando-os por meio de palavras. Acidente ou crime sensacional, morte ou nascimento, divórcio ou casamento, baile ou duelo, concerto ou cena escandalosa, sucesso dramático ou sucesso literário, salão de belas artes ou pistas de corrida, experiências ou 
descobertas científicas, tudo é matéria para o cronista. Sob essa perspectiva, a crônica é considerada uma espécie de "enciclopédia dos tempos modernos".

Com base nas considerações tecidas até aqui, lançamos três perguntas que o presente artigo tentará responder. Como a crônica mundana participa da criação midiática de um imaginário coletivo de modernidade no Rio de Janeiro da Belle Époque? Como esse gênero jornalístico representa o lugar ocupado pela figura feminina na sociedade carioca do período? $E$, por fim, como o esporte se insere nessa dinâmica?

\section{A CRÔNICA MUNDANA}

As crônicas mundanas podem ser consideradas depósitos de literatura. Elas são aleatórias, espaço da causerie ligeira, profusão de detalhes, atualidade e exibição do fútil. O tom confidencial empregado pelo narrador-cronista mergulha o discurso mundano em uma ideologia de identificação comunitária, na medida em que os leitores reconhecem um nome famoso no espaço público. O cronista, formador de opinião, os leva por um passeio pela esfera pública ou pelo o interior dos salões exclusivos e soirées, criando uma atmosfera de familiaridade e identificação. O retrato dos eventos, contudo, não tem compromisso com a totalidade, nem com a veracidade dos fatos. Cabe ao cronista selecionar as informações e ficcionalizá-las, como the aprouver. Frequentemente, o conteúdo das crônicas se relaciona com outras seções do jornal, como o editorial, a página de anúncios ou mesmo as notícias cotidianas, desde que tais informações se mostrem, de alguma forma, relevantes para o público com o qual o autor dialoga. 
Em seu diálogo com o leitor, o cronista o guia pelas experiências vivenciadas na metrópole. O termo mundano é definido pelo Grand dictionnaire universel du XIXe siècle como "Ami des vanités du monde, des chose terrestre et périssable. [...] Qui est futile [...]". A moda, os esportes, os espetáculos e a literatura são consideradas preocupações da vida mundana. Segundo Guillaume Pinson, a mundanidade é um fato social que entrelaça práticas e representações, gestos concretos e discursos. Sua origem partiu das normas da sociedade aristocrática, na França do século XVIII. Os salões do Tout Paris, marcados pelo luxo e pelo divertimento, encenavam a hospitalidade e a distinção na corte, retratados por Anne-Marie Fugier em La vie élégante. Ou la formation du Tout-Paris, 1815-1848 e sociologicamente organizados por Norbert Elias em $A$ Sociedade da Corte. A vida elegante dos aristocratas marca o início de novos códigos de sociabilidade. A adoção dessa nova postura passa a ser intermediada pelo cronista na literatura e na imprensa.

$\mathrm{Na}$ perspectiva da "civilização do jornal" (KALIFA et al, 2011), a sociedade mundana é, simultaneamente, a fonte dos cronistas e o seu público alvo. Podemos defini-la como um conjunto de redes interconectadas: familiares, profissionais, políticas e artísticas, inseridas em um único sistema. Os gêneros da imprensa mundana são responsáveis pela mise-en-scène das múltiplas individualidades pertencentes a um mosaico social. Referindo-se a Marcel Proust e Jean Lorrain como exemplos em língua francesa, Pinson afirma que cronista mundano, a partir de um detalhe captado em sua aparição nos eventos sociais, discorre sobre o mundo do lazer. Consciente da futilidade de seus artigos, o cronista procura entreter a classe ociosa ${ }^{1}$ por meio da 
organização dos discursos de vanguarda e da reconstituição literária do real e da cidade moderna.

Devemos ressaltar que a posição do cronista, ao frequentar os salões e as recepções elegantes, é dual. Por um lado, ele goza de prestígio perante a elite. Os convites para as ocasiões restritas corroboram, de certa maneira, o alinhamento do cronista com os padrões de seletiva sofisticação da elite. Todavia, a integração não é absoluta, pois seu trabalho como repórter da cena de lazer o impede de partilhar os pressupostos da classe ociosa, como define Veblen (1899). O teórico afirma que essa parcela da sociedade se mantém no topo da estrutura social devido à manutenção da capacidade de dedicar-se ao lazer em detrimento do trabalho, considerado desprezível e rebaixado na luta por prestígio e status social. A integração do cronista à lógica do trabalho afasta-o dos requisitos imprescindíveis para manter uma cumplicidade com os membros da elite.

Nesse contexto, a crônica se legitima enquanto espaço de representação de identidades sociais modelares, como as criadas pelos padrões da elegância mundana. Contudo, a condição do seu autor de estar nesse entrelugar permite que haja uma identificação tanto por parte das classes ociosas, quanto das classes trabalhadoras, que desejam alcançar a ascensão social junto com o cronista, por meio da emulação (VEBLEN, 1899). E considerando que a imprensa se desenvolve no âmbito do mercado, a dinâmica de produção comercial incentiva o consumo, ao mesmo tempo, material e imaginário da crônica mundana. De modo que, em seus textos, o cronista concilia a realidade das classes abastadas e a realidade imaginada por aqueles que, por motivos diversos, não a podem experimentar em primeira pessoa.

Com base na noção de transferência cultural proposta por Michel Espagne e Michael Werner (2009), e tendo em vista a 
circulação transnacional dos modelos de sociabilidade de matriz europeia, podemos afirmar que o cronista mundano assume um papel de agente mediador das interações entre diferentes culturas. As nacionalidades dos objetos culturais, tanto as de origem como as de recepção, são híbridas. Segundo os teóricos, não ocorre uma perda semântica no mecanismo de importação, exportação e recepção, já que as trocas permitem acomodações ativas. A ação do cronista pressupõe uma reinterpretação ativa de padrões de sociabilidade, pois realiza um deslocamento entre as condições existentes no lugar de origem e as condições do contexto de acolhimento. E nesse sentido, sua mediação não é tomada aqui enquanto perda, mas enquanto agente da apropriação que gera uma construção nova e produtiva.

No Rio de Janeiro da Belle Époque, os cronistas mundanos difundem os costumes sociais tidos como elegantes. Nas páginas da imprensa periódica, procuram validar práticas modernas, como o footing pela Avenida Central, o flirt, o five o'clock tea nas confeitarias Art Nouveau da Rua do Ouvidor e o consumo das toilettes recém-chegadas de Paris. Os escritores-jornalistas criam, por meio da escrita, a aura de refinamento que envolvia uma presença galante nesses ambientes, estimulando a própria ideia de progresso e civilidade em formação no país. O impulso dado à circulação das pessoas nas ruas é um fenômeno concreto dessa nova sociabilidade na urbe, recentemente reconfigurada pelas reformas de Pereira Passos e Rodrigues Alves. As matérias jornalísticas tratando da presença humana na cidade redesenhada fortaleceu a cultura midiática no Brasil.

Diferentemente das aristocracias europeias oriundas da nobreza que gravitava em torno das cortes monárquicas, a elite carioca da primeira República, desprovida de títulos, 
imaginava um ideal de modernidade e sofisticação, embasado em objetos de desejo e projeções. Buscava constantemente símbolos para corroborar sua superioridade. Para isso, valia-se da importação de uma ideia de civilidade moderna vinda, sobretudo, da Inglaterra e da França. Os hábitos e a aparência afrancesados são exemplos da tentativa de construção de um imaginário coletivo do GrandMonde brasileiro. A crônica mundana afirma-se como meio técnico e poético para representar essa comunidade imaginada conforme discute Benedict Anderson (2008) e propagar um ethos da elegância. A rubrica se estabelece no contexto da cultura midiática no país, sendo a principal expressão escrita das tensões e aspirações de um segmento da sociedade que procurava meios de se manter fechado, restrito e privilegiado, espelhando-se para tanto nos modelos da aristocracia.

O escritor João do Rio foi quem melhor representou as práticas e os anseios mundanos dessa elite social. Costuma ser reconhecido pela historiografia literária e pela antropologia em função do ofício de repórter que exereceu nos grandes jornais da época, como O Paiz e a Gazeta de Notícias (GOMES, 2006; O’DONNELL, 2008). Sua atuação bem-sucedida na introdução da reportagem de rua culminou na publicação de obras que nos legaram um verdadeiro mapeamento da cidade e de seus tipos, a exemplo dos livros As Religiões do Rio (1904) e A Alma Encantadora das Ruas (1908). Entretanto, na fase madura da carreira como escritor-jornalista, afastou-se das ruas e cultivou uma vertente da crônica mais afeita ao luxo e aos salões. Dedicou-se a dar cobertura aos divertimentos da elite, flagrados em crônicas que reuniu nas duas séries: "Pall-Mall Rio" (1916) e "A Semana Elegante" (1916), ambas assinadas sob o pseudônimo José Antônio José. Nessas 
matérias da imprensa, propôs uma nova organização do ócio elegante. Mobilizou recursos jornalísticos e literários por meio dos quais legitimou a formação de um imaginário de modernidade e sofisticação social compartilhado pelas camadas favorecidas do Rio de Janeiro.

\section{A FIGURA FEMININA}

\subsection{A moda e a elegância na crônica mundana}

A imagem feminina é recorrente na obra de João do Rio. Na coletânea de contos intitulada $A$ Mulher e os Espelhos, o protagonismo é quase sempre das mulheres. Nas crônicas mundanas, elas são as principais interlocutoras, às quais o escritor se refere frequentemente pela expressão "minhas queridas leitoras". Em "A Semana Elegante", a construção da interlocução se personifica na constante presença de damas da sociedade, como a da Sra. Renata Gomes e D. Nicola de Teffé. Diante da evidência com que o tema se apresenta, não podemos deixar de apontar a lacuna que ainda persiste nos estudos acadêmicos sobre o autor. É inexplicável que as investigações não focalizem a presença feminina em seus textos.

Para nortear uma primeira incursão no terreno que consideramos abandonado, elegemos a representação de moda feminina como porta de entrada na obra de João do Rio. A escolha não é casual. Em 1911, ele mesmo publicou um livro reunindo algumas de suas concorridas conferências literárias². Desse volume, que se intitulou "Psicologia Urbana", destacamos a conferência "O Figurino" na qual apresenta sua posição diante do mundo das aparências, da imitação e do superficialismo, posição claramente permeada pelos ideais do dandismo. Entusiasmado pela Europa, 
exaltou Paris como farol da elegância: "Oh! É preciso ter estado na Cidade Luz para compreender a Moda e a criação de um Figurino. Há Londres, há Milão, há Viena, há mesmo a Alemanha inteira. Para essa obra delicada e formidável, porém, só Paris." (RIO, 2015, p. 114). A visão de João do Rio acerca de Paris como o centro irradiador de moda fica evidente na assertiva. Sua voz em defesa da elegância francesa, em concordância com as vogas da indumentária feminina, se levanta como um emblema do próprio projeto civilizatório da Belle Époque brasileira.

Dentre a sua extensa produção jornalística e literária, destacamos a coluna "A Semana Elegante", publicada sob o pseudônimo José Antônio José na Revista da Semana, durante o ano de 1916. Com a discussão de temas mundanos, essas crônicas compõem um retrato de práticas elegantes que ajudaram a forjar o imaginário social. Seu conteúdo difere do caráter pedagógico dos textos geralmente presentes nas revistas femininas e nos periódicos. Publicações como A Mensageira (1897) e Jornal das Famílias (1863) voltavam-se para a leitora "escolarizada, atenta às modas e figurinos de seu tempo" (MARTINS, 2001, P. 377). Nelas, os colunistas discutiam assuntos relativos à moda, à higiene, orientação de cuidados com a prole e de manutenção do lar. Esses veículos difundiam uma mensagem educacional da moda, ensinando diretamente a leitora a costurar seus próprios trajes. Neles, o discurso da moda apresenta um sentido de construção material da roupa. Como consequência, os editores preteriam a dimensão simbólica da indumentária. Isso fica evidente na estrutura dos textos e nas escolhas lexicais, conforme constatamos na legenda de um molde publicado no Jornal das Famílias, em 1864: 
Este vestido, cujo desenho nos foi pedido, e que poderá agradar a mais de uma de nossas assinantes, por ser muito de moda neste momento, é destinado a ser feito de tafetá preto e em bordado real com seda preta; as pétalas das flores fazem-se quer com contas de vidrilhos, quer com nozinhos. O corpinho é bordado nas frentes, e atrás ao redor do pescoço; as mangas são bordadas nos canhões. Toda a frente da saia é bordada em forma de avental, o bordado forma canto de cada lado e segue toda a roda. (O JORNAL DAS FAMÍLIAS, 1864, p. 22).

A descrição da indumentária, aqui, é objetiva e prática. Nesse fragmento cuja autoria não está identificada, o vestido centraliza a descrição. Para atender ao mencionado desejo da leitora, os materiais e as técnicas necessários para a reprodução da peça são explicados. Apesar da riqueza de detalhes, não há menção aos sentidos produzidos pelo ato de vestir e seu impacto interior, relacionado à construção de uma identidade, e seu impacto exterior, de conformidade social. A ausência de uma caracterização atrelada ao vestuário escrito direciona o olhar para a leitura da moda como objeto material, meramente utilitário, desprovido de significações.

Ora, o consumo das roupas, caso fossem inseridas na dinâmica da sociedade industrial, como mera necessidade de proteção do corpo, se faria em ritmo lento, ditado pelo desgaste da matéria prima. Por outro lado, a urgência, a ânsia por novos produtos, concebe um simulacro do objeto real, somando às roupas imagens, razões e significados, que apelam à consciência do consumidor. Segundo Barthes (2009), "o que faz desejar, não é o objeto, é o nome; o que faz vender não é o sonho, é o sentido.". O consumo de moda não é só material. Também é figurado e representa a posse de valores de civilidade e progresso. Assim, A relação da roupa com a personagem que a veste, o contexto de uso e 
os efeitos provocados no observador indicam sentidos, que compõem o imaginário coletivo.

Tal reflexão levanta uma indagação acerca do papel do vestuário escrito, segundo o conceito de Barthes. Enquanto o vestuário real possui funções práticas, como a proteção, o pudor e o adorno, essas funções não se aplicam ao vestuário escrito, que não possui nenhuma aplicabilidade tangível. Nesse aspecto, "a descrição de Moda não tem a função apenas de propor um modelo à cópia real, mas também e, sobretudo, de divulgar amplamente a Moda como um sentido." (BARTHES, 2009, p. 29.). No contexto da Belle Époque carioca, João do Rio aproveitava-se da descrição da indumentária para sistematizar condutas e atribuir qualidades distintivas, de acordo com os lugares econômicosociais e os papéis desempenhados no espetáculo urbano. 0 cronista mundano atua na circulação da moda enquanto símbolo da novidade e do bom gosto das mulheres elegantes, assumindo a função de agente mediador das transferências culturais.

\subsection{O corpo em cena}

Como o corpo feminino, suporte do vestuário, era representado nos periódicos? Não se pode pensá-lo apenas como materialidade biológica, composta por órgãos, pele e sentidos. É necessário tomá-lo na perspectiva da cultura e da linguagem, considerando fatores sociais que o formam. A percepção do corpo feminino não é universal, uma vez que tempo, espaço, conjuntura econômica e grupos sociais podem modificá-lo. No contexto da Belle Époque carioca, o ideal de modernidade e as novas práticas da classe ociosa 
tiveram influência sobre os padrões estéticos relativos ao corpo.

A circulação das teorias positivistas e darwinistas inspiraram transformações. O avanço da ciência na área da saúde, aliada a uma preocupação sanitarista, afetou a concepção do corpo na sociedade. Por se tratar de uma questão central da vida urbana, a instância política intervinha na vivência da corporalidade. Exemplares quanto às mudanças são as medidas que tornaram obrigatórias a vacinação e a promoção dos hábitos de higiene. Na imprensa da época, encontramos campanhas em defesa do projeto de imunização coletiva, da higienização das ruas - com a proibição da criação de animais no perímetro urbano e o calçamento dos passeios públicos - e o anúncio constante de produtos de beleza voltados ao cuidado do corpo, como sabonetes e perfumes.

Os periódicos também revelam as marcas da representação positivista dos corpos femininos, inspiradas nas ideias de salubridade e asseio. As convicções positivistas incentivam o cuidado com o corpo. A valorização da constituição física se manifesta na valorização da magreza e nos espaços simbólicos que o corpo feminino ocupa na estrutura social.

\subsection{As práticas esportivas na Belle Époque.}

Veículos da modernidade, os impressos ajudam a construir um imaginário de sociedade saudável, em sintonia com a voga cientificista. O olhar dos cronistas se dirige para um novo campo: o das práticas esportivas. No início do século XIX os esportes expandiram-se entre os grupos que reproduziam os hábitos aristocráticos. A difusão do gosto 
pelos exercícios físicos ganhou uma intensa repercussão na imprensa. Segundo o estudo de Ana Luíza Martins, surgiu um manancial de revistas temáticas em resposta direta ao crescente interesse pelos esportes, revistas voltadas aos mais diversos públicos. Revistas como A Bicicleta - réplica quase fiel da francesa Bicyclette - e O Sport compunham o espectro diversificado das publicações esportivas no Brasil.

A rápida difusão do gosto pelas práticas esportivas decorre da expansão da imprensa, que promoveu a circulação transatlântica das informações sobre essas práticas. As primeiras corridas de bicicleta e os primeiros matchs de tênis ocorreram na Inglaterra no século XIX e foram rapidamente incorporados na França. A Exposição Universal de 1900, realizada em Paris, foi o primeiro evento de escala mundial a dar visibilidade às práticas esportivas: "Included in the programme of the exhibition were Concours internationaux d'exercices physiques et de sports, reflecting the serious status of sport and health in the minds of the French elite" ${ }^{\prime 3}$. A partir do evento parisiense, o número de praticantes e o mercado de produtos para a prática dos esportes passou a experimentar um crescimento acentuado.

No Brasil, a cobertura textual e fotográfica das Exposições Universais compunha a práxis da imprensa, devido ao seu caráter laboratorial e exibicionista dos avanços técnicos nela apresentados. As informações difundiam entre os leitores o ideal de progresso e de modernidade estética que deveria ser alcançado, em especial no Rio de Janeiro, a vitrine do país. A circulação das informações elevara-se a uma escala antes impensável, de perspectiva sistêmica global, após a instalação das redes telegráficas continentais e intercontinentais, em especial com a instalação do cabo transoceânico, em 1866. Houve uma modificação extraordinária do espaço-tempo na 
propagação da informação. É consensual considerar que a chegada dos programas de exercícios físicos e as práticas dos esportes ao Brasil tenham ocorrido simultaneamente à sua explosão na Europa, via imprensa.

$\mathrm{Na}$ revista ilustrada Fon-Fon, um anúncio da loja de departamentos Casa Colombo proclama: "O esporte é o segredo da longa juventude!". As corridas de cavalo no Jockey Club, as partidas de tênis no Icaraí, as disputas de remo no Clube de Regatas, as competições de ciclismo e os banhos de mar exemplificam a adoção das práticas esportivas no Rio de Janeiro da Belle Époque e tornam-se temas para as crônicas mundanas.

$\mathrm{Na}$ Inglaterra e na França o movimento de disseminação dos esportes deu origem à instalação de unidades fabris para suprir as demandas geradas por um mercado inédito. Surgiram magazines esportivas como Agence générale des Sports e GeoG. Bussey et $C^{\circ}$ de Londres. Nos endereços parisienses, encontravam-se artigos esportivos para 0 ciclismo, esgrima, ginástica e tênis. Entre as inovações, os tecidos à prova d'água, vendidos como higiênicos e apropriados para a permanência ao ar livre. Na dinâmica da distinção, vestir as novidades demonstrava afinidade com os ideais de progresso valorizado na capital: (BOURDIEU, 2007).

No cotidiano de lazer, as modas esportivas sucediam-se passageiras, novidades fugazes, festejadas, rendendo matérias de agrado da elite, que comparecia aos selecionados eventos para ver e ser vista (...). (MARTINS, 2001, p. 341)

Sabemos que a moda esportiva busca conciliar duas vertentes. Por um lado, expressa a circunstância prática de sua demanda. A inserção dos esportes no dia a dia evidencia, portanto, que as mulheres sentiam a necessidade 
de dar mobilidade ao corpo. Os trajes de passeio ainda reprimiam grande parte dos movimentos devido à quantidade de tecido e aos cortes constritivos. A adoção de cortes mais justos e tecidos mais maleáveis facilitava as atividades. Além disso, a adaptação à água e a proteção contra o sol também eram preocupações práticas. Esse conjunto de exigências induzia ao consumo dos novos produtos que o mercado passava a oferecer.

Por outro lado, os aspectos da materialidade da moda esportiva combinavam-se com a dimensão simbólica, que visava o pertencimento a um grupo social. O consumo e o uso desses trajes específicos indicam a distinção de seus portadores, supostamente pertencentes à classe ociosa, que podia dedicar seu tempo livre ao aperfeiçoamento do corpo e da saúde. A aparência característica dessa indumentária simboliza ainda a modernidade e o progresso no espaço público urbano. Por isso, a ficcionalização da moda esportiva nas rubricas de crônicas mundanas constrói e valida a inauguração de uma nova instância de sociabilidade.

\section{A FICCIONALIZAÇÃO DA MODA ESPORTIVA NAS CRÔNICAS DE JOÃO DO RIO}

\subsection{O tênis}

As práticas esportivas aparecem nos textos de João do Rio, conforme podemos verificar na crônica "Tênis", publicada na edição número 31, do dia 09 de setembro de 1916. Mais curta do que a maioria das crônicas mundanas da sua coluna na revista, é acompanhada por fotografias de mulheres jogando tênis. Optamos por dividir a análise em dois pontos, que estão em constante comunicação: a leitura do vestuário-escrito e, em seguida, a do vestuário-imagem. 
A proposta segue o plano barthesiano de composição do "sistema da moda" a partir do vestuário-escrito. O conteúdo visual constitui uma adição pertinente, diante da proposta de analisar a aparência da figura feminina.

João do Rio inicia sua incursão no tênis ao constatar a presença da prática desportiva entre as mulheres da elite. $\mathrm{O}$ termo "enfim" expressa o atraso na adoção da: "Enfim as encantadoras convenceram-se de que era necessário adotar um sport. E esse sport insensivelmente vai sendo o lawntennis." (A REVISTA DA SEMANA, 1916, n. 31). A necessidade do exercício físico, declarada pelo cronista, origina-se no anseio coletivo das mulheres de estarem em sintonia com os parâmetros europeus. Na construção textual, a valorização do estrangeiro é reforçada pelo emprego das palavras sport e tennis em inglês. A escolha do tênis denota um projeto de validação da importação de costumes, considerados civilizatórios, como recurso para obter distinção social. Esse projeto permeia toda a coluna "A Semana Elegante". Como o cronista afirma, "O sport serve além disso ao moral. Dá afirmação, desembaraço, enche de galhardia, aclara as ideias." (A REVISTA DA SEMANA, 1916, n. 31) O tênis seria um caminho para o melhoramento do espírito do praticante e para o reforço da moral coletiva, devido à possibilidade de integração social.

O cronista sugere um novo padrão de beleza. Utilizandose do diálogo com uma personagem, a crônica divulga indícios de um culto ao corpo. O padrão estético se sustenta em um discurso que o associa à saúde. "(...) os grounds de Paysandú prepararam campos bem marcados e pela manhã são muitas já as verdadeiras encantadoras, senhoras e senhorinhas que reforçam os músculos e vitalizam o corpo nessa elegância inglesa." (A REVISTA DA SEMANA, 1916, n. 31). Segundo ele, engordar seria o futuro mal da brasileira, 
por isso, os exercícios se mostram como o único modo para evitar o sobrepeso. O cronista corrobora a linha de pensamento de que os esportes não constituem apenas um novo espaço de sociabilidade e de demonstração da elegância, mas oferecem também o sustentáculo e a solução para a definição de uma estética moderna do belo associado à figura feminina.

A menção à preocupação com as formas corporais remete à relação que se estabelecia, na época, entre o padrão estético do corpo e os parâmetros de salubridade, amplamente defendidos nas medidas políticas, culturais e econômicas adotadas no Rio de Janeiro. Os discursos higienistas atrelados à medicina, ao mesmo tempo em que embasavam as sucessivas políticas de reordenação das normas de habitação da região central, associavam-se a novas formas de sociabilidade, e, em particular, às práticas desportivas. O corpo feminino ganhava um espaço significativo no cenário carioca. Espaço que pode ser pensado em sua materialidade, ocupando as vias públicas, e em uma perspectiva simbólica, incorporado às representações literárias e midiáticas.

Detectamos no discurso de João do Rio a ratificação de um ethos cosmopolita da cidade do Rio de Janeiro através da difusão de novas dinâmicas socioculturais. A associação que ele faz entre o mal do sedentarismo, que acomete o corpo, e o estado de alma, mostra a sintonia do cronista com o projeto político que buscava instituir os moldes da civilização moderna na cidade.

Outro ponto relevante para o exame aqui proposto é a caracterização do jogo de tênis como "elegância inglesa". O projeto modernizador proposto por João do Rio dialoga com as práticas da classe ociosa no contexto europeu. O cronista mundano demonstra a assimilação de práticas culturais 
consideradas elegantes por uma camada endinheirada da sociedade. A encenação da modernidade parte da "[...] ideia de criar aqui mesmo no Rio do divino prazer." (A REVISTA DA SEMANA, 1916, n. 31). Trata-se, portanto, de uma tentativa de representação do alinhamento aos modelos europeus de civilização e de modernidade, ainda que inserindo toques de cor local.

O flanêur parte de um encontro casual com a personagem feminina para descrever o vestuário-escrito. "A sra. Renata Gomes, fui encontrá-la de sapatos baixos, vestida de brim, com uma sweater de lã leve e rubra e uma raquete na mão." (A REVISTA DA SEMANA, 1916, n. 31). A narrativa dos trajes da personagem é breve e sucinta. $O$ ponto central reside no acessório: a raquete que ela segura. É o objeto que permite identificá-la com a prática do tênis. O porte da raquete atesta o propósito da mulher e demonstra sua filiação aos ideais de salubridade e atualidade já apresentados.

Os sapatos baixos se opõem aos saltos utilizados nas recepções, bailes e teatros. A demanda pela mobilidade e pelo conforto durante o jogo exige uma ruptura com o préconceito de que apenas os sapatos de salto alto simbolizavam a elegância, enquanto os sapatos baixos se destinavam às práticas campestres. Torna-se viável uma nova aspiração fashion: a sofisticação da adequação. Mais importante do que o valor estético e simbólico de elegância atribuído ao salto, a adaptação às novas práticas e aos novos espaços converte-se em sinal de modernidade.

João do Rio discute o tecido do figurino. "Vestida de brim" indica uma oposição à toilette convencional do ócio elegante. O brim é um tecido feito de algodão. Resistente, costumava ser destinado à produção dos uniformes usados pelos trabalhadores nos séculos XVIII e XIX. Os trajes 
brancos, que sujam facilmente, se convertem em símbolos dos ricos, assim como o próprio tênis, pois demandavam delicados e dispendiosos cuidados com limpeza e manutenção. O vestido era acompanhado pela sweater, novamente grafado em inglês, para reforçar a importação dos moldes de civilização. Há uma aclimatação para a realidade carioca, quando o cronista menciona o adjetivo "leve". Ao invés de se abrir mão da peça de roupa, esta é transformada. Por efeito do clima tropical, fazia-se necessário substituir a lã pesada, usada nos países do Hemisfério Norte, por um material mais leve. A substituição do tecido mostra-se uma boa alternativa para a adequação, de modo que o visual ainda se mantivesse e estampasse os mesmos valores.

As fotografias que contornam a página da crônica ilustram o vestuário-escrito da Sra. Renata Gomes. As dez mulheres representadas seguram raquetes, assinalando a relação com o tênis. Vale ressaltar que a maioria foi fotografada em movimento, explicitando a questão da visibilidade e da saúde do corpo feminino. Todas vestem tons claros, o que corrobora o que foi dito acerca do imaginário do esporte, reforçado pelo traje branco obrigatório nas partidas de Wimbledon, até hoje o mais importante torneio de tênis do mundo. As saias ainda são longas, mas não são muito rodadas, nem muito retas, o que facilita o jogo. Apesar disso, a cintura fortemente marcada indica a feminilidade, expondo as linhas do corpo da mulher, em sintonia com a estética predominante na década de 1910. Por fim, algumas toilettes são acompanhadas por chapéus, que protegiam a pele da exposição ao sol, mantendo o ideal de pele alva veiculado nos círculos europeus. 
A aproximação do vestuário-escrito e 0 vestuário imagem, entre o texto e visualidade, constrói um imaginário coletivo intermediado pela moda esportiva. Os símbolos, como a raquete e as roupas brancas cristalizam um ideal de civilidade moderna, legitimando o tênis como uma prática de lazer elegante no Rio de Janeiro do início do século XX.

\subsection{Os banhos de mar}

A instalação das primeiras linhas do bonde, em 1892, inaugura a expansão do Rio de Janeiro em direção à Zona Sul. Na virada entre o século XIX e o XX, a circulação de pessoas pela cidade se intensificou devido ao uso dos novos meios de transporte coletivo. Segundo a antropóloga Julia O'Donnell, "[...] os bondes sintetizavam boa parte dos signos da urbanização e, na mesma medida, de determinado ideal de modernidade." (O'DONNELL, 2013, p. 22). Iniciouse um processo de construção imaginária do balneário, introduzindo a estética de cidades litorâneas como Cannes, Nice e Biarritz.

Na crônica "A paixão pelo mar", publicada em 11 de março de 1916 (ed. 05), o autor discute a nova moda dos banhos de mar. A prática era recomendada pelas autoridades médicas, que a justificavam com base nos avanços científicos e no higienismo, ideal articulador da vida moderna. João do Rio abre a coluna com a afirmação: "Enfim, parece certo que a paixão pelo mar entrou na moda! Com estes dias de intenso calor e de céu ardente, o interesse mundano não é a vilegiatura na montanha, mas principalmente as praias de banho, as nossas maravilhosas praias, as mais belas do mundo!". Apontamos para a repetição do termo "enfim", retomando a noção de um 
subdesenvolvimento que vinha sendo vencido pelo projeto civilizatório da cidade. Com o desbravamento da Zona Sul, esperava-se inventar o ideário de um paraíso balneário, acompanhado por uma sociabilidade moderna.

"Nós somos melhores quando contemplamos o mar. Olhá-lo é tonificar o espírito como respirá-lo é adquirir a saúde do corpo." (A REVISTA DA SEMANA, 1916, n. 05). Nesse fragmento, o próprio cronista associa o mar à questão da salubridade do corpo e do espírito. A associação é equivalente à do jogo de tênis. Havia um consenso ao redor dos benefícios das práticas esportivas, as quais serviam ao propósito simbólico de conectar um conjunto de pessoas que aceitavam o discurso higienista como verdadeiro.

Talvez o desejo de distinção originasse essa convicção. O tempo livre para a apreciação das atividades junto ao mar caracterizava aqueles que podiam se aproveitar do meio do dia, em oposição aos trabalhadores que tomavam um rápido banho de mar antes do trabalho e se arrumavam nos cubículos apertados das casas de banho. Como declara João do Rio, "O prazer agora é correr às praias, tomar banho de mar, comunicar com o ócio, pela manhã e tarde." (A REVISTA DA SEMANA, 1916, n. 05). A vivência balneária apoia-se no discurso da salubridade e na difusão de práticas modernas do ócio elegante.

A beleza natural das praias refletida pelo "[...] dilúvio azul de Icaraí, sonho de pérolas do Flamengo, a madrépora verde clara de Copacabana." (A REVISTA DA SEMANA, 1916, n. 05) se mostrava em paralelo com os balneários europeus. Segundo João do Rio, "A linha de Copacabana reproduz um trecho de Biarritz." (A REVISTA DA SEMANA, 1916, n. 05). A importação de um ideal se manifestava na importação de pedras portuguesas para o calçamento icônico da orla de Copacabana, incrustradas por trabalhadores vindos de 
Lisboa exclusivamente para a tarefa e pela posterior construção do hotel Copacabana Palace, para acomodar os visitantes estrangeiros na Exposição Mundial de 1922.

Uma miríade de significados acompanha o figurino do tênis e os trajes de banho. A questão do corpo, apesar de central, não é mencionada pelo cronista na crônica. A exibição da figura feminina era considerada tabu devido aos paradigmas de moralidade. Em 1916, ainda não havia a campanha a favor dos maiôs, os quais só foram popularizadas no início da década de 1920. O cronista não descreve em detalhes as toilettes do balneário. As duas fotografias que complementam a crônica facilitam a leitura do figurino da encenação elegante do balneário proposta por João do Rio.

A toilette de banho era composta por um vestido e espadrilles. O vestido sem mangas evidenciava o colo nu. Em ambas as fotos, tem-se a cintura marcada e o comprimento da saia alcança o joelho. As tiras de amarração das espadrilles enfeitam os tornozelos e, na segunda imagem, a mulher usa uma espécie de touca nos cabelos, provavelmente, para evitar que se molhem. Tal como o vestuário do tênis, identificamos a preocupação com a adequação à prática. Embora não haja uma resenha do tecido, deduzimos a escolha de um material que secasse rápido, por razão de higiene e conforto térmico. Os sapatos, sem salto, adequavam-se ao footing na areia. A falta de acessórios justifica-se por sua incompatibilidade com o banho de mar. A uniformização dos trajes de banho pode ser interpretada como um indício de um repertório de um grupo elitizado, mostrando pertencimento e identificação. A expressão da individualidade feminina ficava a cargo das interferências nas listras dos vestidos e nas fitas e desenhos na parte superior dos calçados. 
"Este verão, meu amigo, trouxe definitivamente para o Rio mundano a paixão pelo mar! é de todas as modas do Rio a mais deliciosa." (A REVISTA DA SEMANA, 1916, n. 05). Diante da articulação entre o vestuário imagem e a narrativa da sociabilidade na qual estava inserido, constatamos a importância da crônica mundana para a representação da vivência balneária como um passo rumo ao progresso civilizado.

\section{CONCLUSÕES}

No decorrer do século XIX, a leitura dos periódicos se estabelece como o principal agente de organização do tempo e de regulação das práticas e representações sociais. Os impressos tornam-se inventários dos costumes e dos interesses coletivos, na medida em que reuniam individualidades em uma coletividade heterogênea e fragmentada, composta por pessoas que compartilhavam uma realidade imaginada.

A intensificação das transferências culturais atua na importação de padrões e valores que alicerça a imaginação dessa sociedade. A apropriação e aclimatação das práticas esportivas no Rio de Janeiro da Belle Époque encenam um novo leque de atividades para preencher o tempo livre e novos espaços de sociabilidade, que desencadeiam representações corporais e da moda. Os corpos vestidos e em movimento, assim como a composição narrativa do vestuário, do tênis e dos banhos de mar fortalecem, no Brasil, a percepção de consonância com os ideais de progresso e civilização europeus.

O resultado é observado na invenção de um imaginário de modernidade e elegância embasado no comportamento 
social por meio da literatura. A circulação da moda esportiva na crônica mundana fundamentava uma pluralidade de sentidos que a elite desejava manifestar. As preocupações com a salubridade e o desejo de distinção social cristalizam um conjunto de práticas e representações esportivas, inventando um novo imaginário do ócio elegante da modernidade.

\section{Notas}

1 No decorrer do artigo, usaremos as expressões "classe ociosa" e "classe de lazer" para nos referirmos ao conceito sociológico definido por Thorstein Veblen em A teoria da classe ociosa.

2 As conferências também eram um espaço de sociabilidade em voga naquele momento.

3 "Incluído no programa das exibições estava o Concurso internacional de exercícios físicos e de esportes, refletindo a séria preocupação com os esportes e com a saúde nas mentes da elite francesa." Tradução nossa.

\section{Referências}

A REVISTA DA SEMANA. Rio de Janeiro. 1916, nº 05 e 31.

O JORNAL DAS FAMÍLIAS, Rio de Janeiro, 1864.

ANDERSON, Benedict R. O'G. Comunidades imaginadas: reflexões sobre a origem e a difusão do nacionalismo. Tradução de Denise Guimarães Bottman. São Paulo, SP: Companhia das Letras, 2008. 330 p.

BARTHES, Roland. Sistema da Moda. São Paulo, Editora WMF Martins Fontes, 2009. 301 p.

BENJAMIN, Walter. Charles Baudelaire, um lírico no auge do capitalismo. Trad. José Martins Barbosa e Hermerson Alves Batista. São Paulo: Brasiliense, 1989. (Obras escolhidas, v.3)

BENJAMIN, Walter. Rua de mão única/Walter Benjamin. 5.ed. Trad. Rubens Rodrigues Torres Filho e José Carlos Martins Barbosa. São Paulo: Brasiliense, 1995. (Obras escolhidas, v.2) 
BOURDIEU, Pierre. A distinção: crítica social do julgamento. São. Paulo: Edusp; Porto Alegre, RS: Zouk, 2007. 556p.

CARASSUS, Émilien. Le snobisme et les lettres françaises: de Paul Bourget à Marcel Proust. Paris: Librairie Armand Colin, 1966. $639 \mathrm{p}$.

ESPAGNE, Michel. Transferts culturelles et histoire du livre. Histoire et civilisations du livre. Revue internationale. Genebra: Librarie Droz, 2009, pp. 202-218.

GOMES, Renato C. João do Rio: vielas do vício, ruas da graça. Rio de Janeiro, Relume Dumará, 1996.

JAMAIS-SAMSON, Sandrine, TERRET, Thierry. Fabricants, détaillants et vendeurs : l'économie du costume de sport à la Belle Époque. Staps, vol. 83, no. 1, 2009, pp. 55-67.

LA CIVILISATION du journal: histoire culturelle et littéraire de la presse française au XIXe siècle. Direção de Dominique Kalifa. Paris: Nouveau Monde, 2011. 1762 p., il. (Opus magnum).

LEVIN, Orna. As figurações do dândi: um estudo sobre a obra de João do Rio. Campinas, Editora da Unicamp, 1996.

MARTINS, Ana Luiza. Revistas em revista: imprensa e práticas culturais em tempos de República, São Paulo (1890-1922). São Paulo, SP: Edusp; 2001.

O'DONNELL, Julia. A invenção de Copacabana: culturas urbanas e estilos de vida no Rio de Janeiro (1890-1940). Rio de Janeiro, RJ: Zahar; 2013.

O'DONNELL, Julia. De olho na rua: a cidade de João do Rio. Rio de Janeiro, Jorge Zahar Ed., 2008.

PINSON, Guillaume. Fiction du monde: De la presse mondaine à Marcel Proust. Montréal: Presses de I'Université de Montréal, 2008.

THÉRENTY, Marie-Ève. Pour une histoire littéraire de la presse au XIXe siècle. Revue d'histoire littéraire de la France, vol. vol. 103, no. 3, 2003, pp. 625-635.

VEBLEN, Thorstein. A teoria da classe ociosa: um estudo econômico das instituições. 2. ed. São Paulo, SP: Nova Cultural; 1987. 


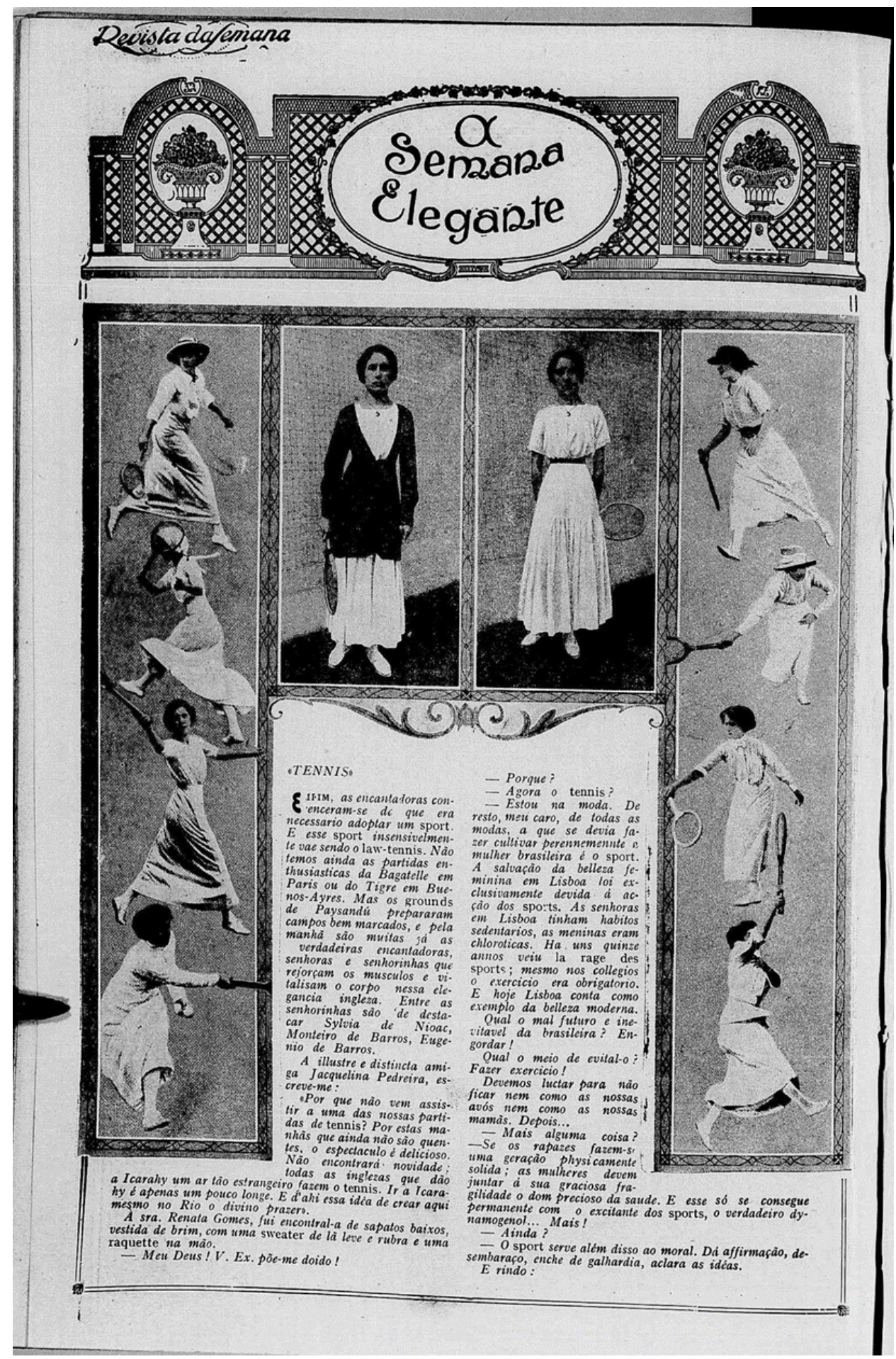

A REVISTA DA SEMANA. Rio de Janeiro. n. 31, 09 set. 1916. 


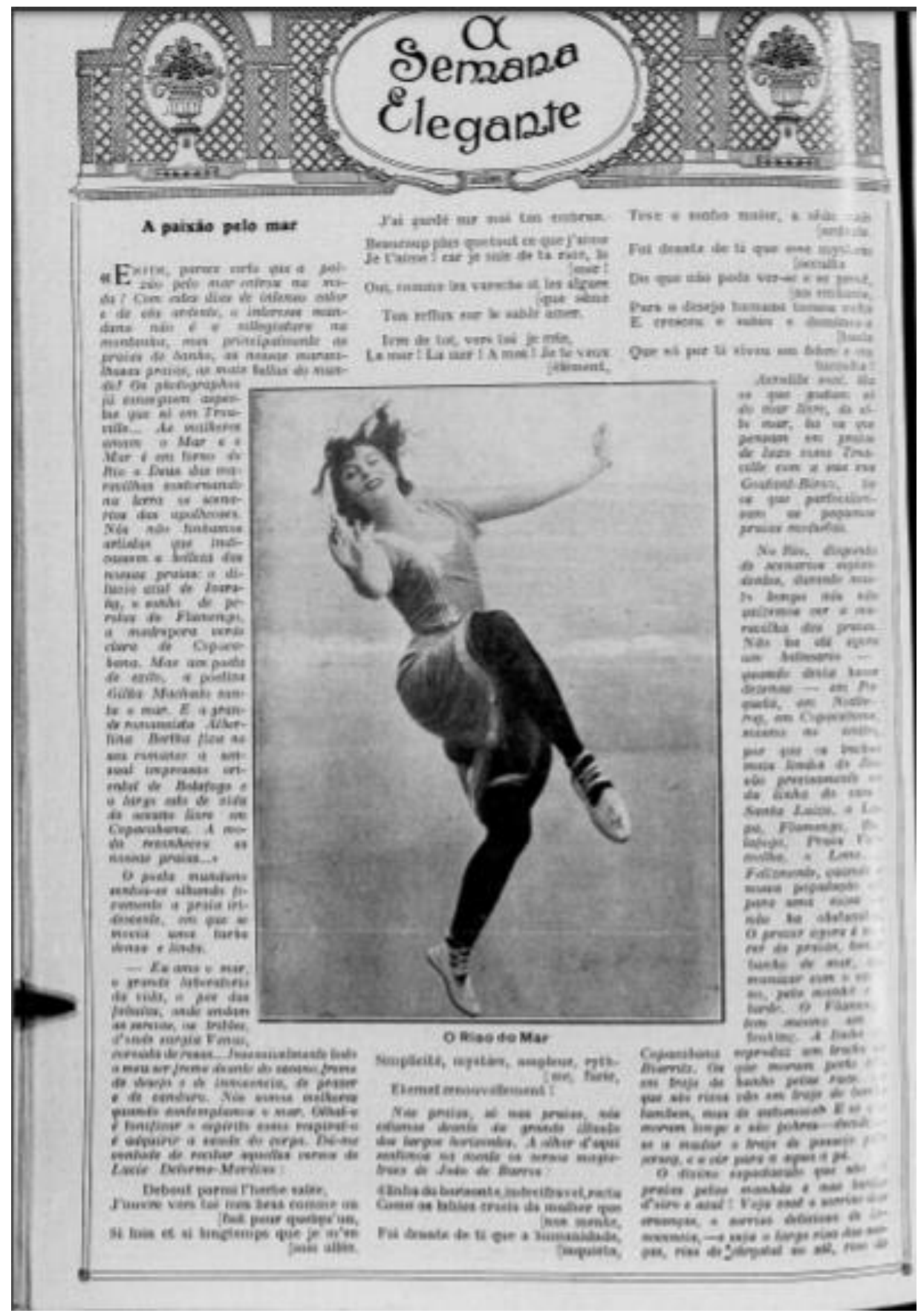

A REVISTA DA SEMANA. Rio de Janeiro. n. 05, 11 mar. 1916. 


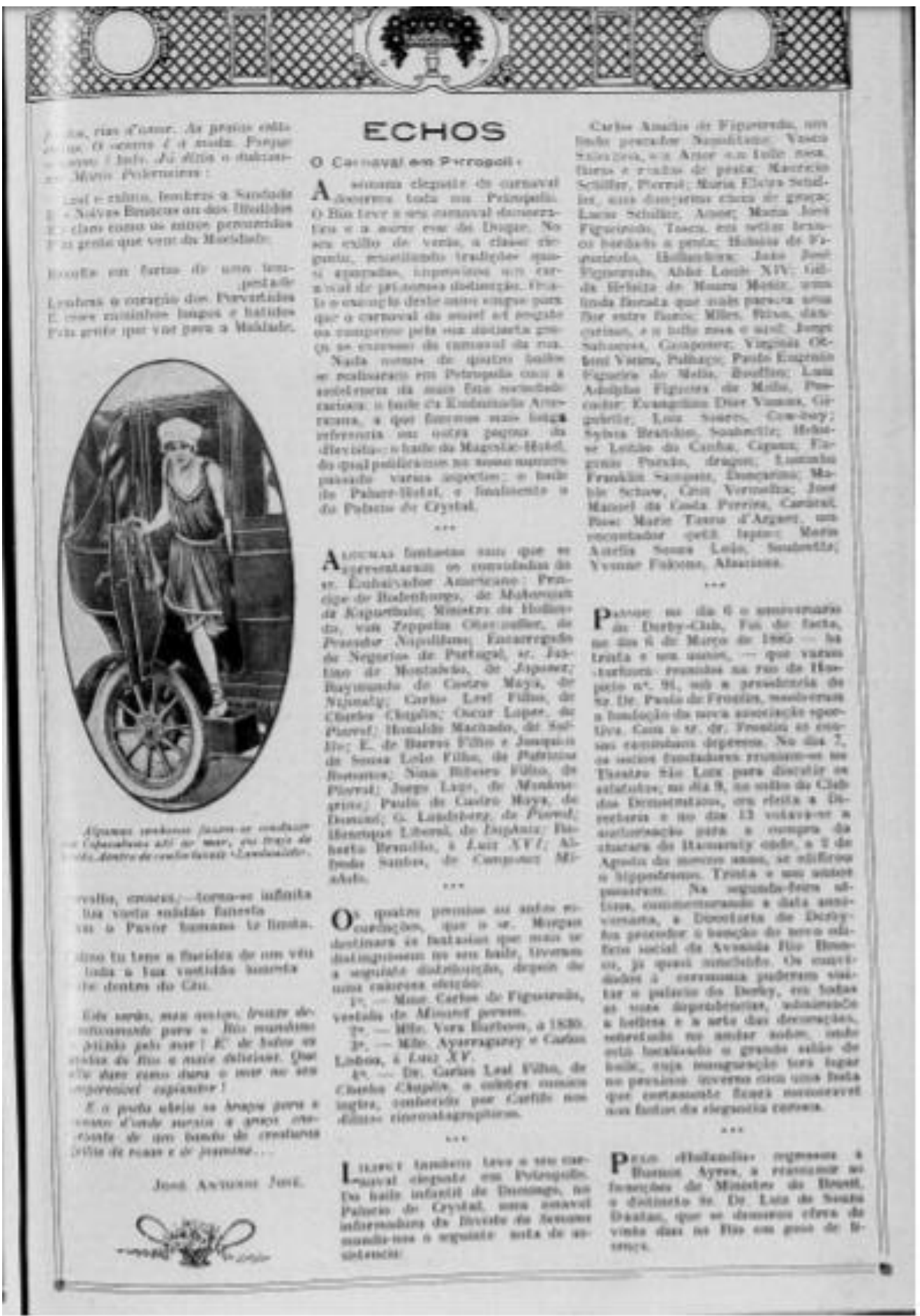

A REVISTA DA SEMANA. Rio de Janeiro. n. 05, 11 mar. 1916. 